\title{
Back to Basics of Informing: The INIS Principle
}

\author{
Bob Travica \\ University of Manitoba, Winnipeg, Manitoba, Canada \\ btravica@cc.umanitoba.ca
}

\begin{abstract}
The term "information" pervades both the mundane and technical vocabularies to the extent that it resembles an infomantra. It is argued in this article that despite the wide spread of this infomantra, the term "information" does not communicate well to the client of informing since the informer uses it arbitrarily and without regard for the effects of informing. Conceptual in character, this argument is complemented by evidence from (1) evaluating user interface of Websites and (2) analyzing academic articles. A reified concept of information and an informer bias are identified in both domains as the antecedents to infomantra. In self-defense, the subjugated client may seek shelter of the INIS principle (It's not information, stupid!). However, opportunities for escape are also identified in Website design and in possibilities of deeper theorizing of information.
\end{abstract}

Keywords: information, meaning, knowledge, data, informing, communication, Web evaluation

\section{Introduction}

The term "information" has become pervasive in everyday speech, professional jargons, and academic vocabulary. Everybody seems to be in the business of "providing information" in everyday life, in professional contexts, in science, and so on. Everybody talks about "information" ("Do you have information on...? I sent you information... For more/your information... Thank you for your information on"...). Everything and everyplace "has" or claims "info" (Websites, social media, smart phones, computers, business documentation, global electronic supply chains, etc.). It appears that many people have almost lost the ability to express themselves without using "information". Instead of naming in specific terms what is communicated or referred to (question, answer, news, instruction, explanation, description, guide, list, plan, stock quote, customer address, sales report, income figure, etc.), all this and more is usually stamped with the all-inclusive term "information".

The eleven-letter word "information", which counters the trend of minimizing text on shrinking and increasingly crowded electronic displays, has become an umbrella covering any conceivable content. Indeed, its persistent use resembles an infomantra that reverberates through the world. The mainstream academic literature in the areas of information systems (IS) and management contributes to this infomantra. Instead of

Material published as part of this publication, either on-line or in print, is copyrighted by the Informing Science Institute. Permission to make digital or paper copy of part or all of these works for personal or classroom use is granted without fee provided that the copies are not made or distributed for profit or commercial advantage AND that copies 1) bear this notice in full and 2) give the full citation on the first page. It is permissible to abstract these works so long as credit is given. To copy in all other cases or to republish or to post on a server or to redistribute to lists requires specific permission and payment of a fee. Contact Publisher@InformingScience.org to request redistribution permission. precision and terminological differentiation based on clear theoretical foundations, this literature operates with simplistic, often tacit assumptions and models. The typical resulting problems are that "information" is neither formally defined nor differentiated from data and knowledge (Kettinger \& Li, 2010; Knox, 2009; Machlup, 1983). 
Apart from homogenizing the language into mantric monotony, is there any deeper problem associated with this "infomantra" language? Do not we live in the "information age" in which "information" is the key resource, competitive weapon, lifeblood of organization, common currency, and such? Does not sharing of the term "information" across various walks of life enable better mutual understanding? Without denying the idea of "information age", I intend to argue that the infomantra fuels confusion rather than clarity in communication. More often than not, the use of "information" appears thoughtless, as a handy choice that can mean different things to different informers and clients. Consequently, the informer can "provide information" that does not inform whatsoever as the client does not understand the communicated content. However, this possibility at best is at margins of attention of the "information provider" who invokes "information" by automatically extending organizational lingoes or by following opaque subjective reasons.

The mainstream academic literature in IS is likely to share a conception that information equals organized and meaningful data (Chaffey \& Wood, 2005; Hislop, 2005). However, neither the organizational aspects nor the test of meaningfulness is theorized sufficiently or investigated. IS are assumed to "provide" information, but modeling this "provision" is rather meager. Some inroads into understanding data organization accrued from applications of speech act theory (Winograd \& Flores, 1986) and study of communication genres (Orlikowski \& Yates, 2004; Päivärinta, 2001). But IS research typically leaves information issues out of picture and simply presumes that IS "provide" information by the virtue of mere existence. Information is then manipulated (sent, given, gotten, owned) as any other material asset. Faced with this literature that trades hypothesis for scientific proof, the academic client (the reader) can just rely on faith.

If infomantra presents a notable practical and theoretical problem, we need to pay more attention to it and to understand it better. This study investigated some manifestations of the excessive use of "information" (infomantra) and the background reasons.

\section{Methodology}

The research problem explored in this study is the excessive use of the term "information" (infomantra) and its antecedents. In exploring the problem, I conducted (1) evaluation of menus at Websites with regard to their use of the word "information" and (2) an analysis of academic uses of the term "information".

Since the goal was to supplant evidence to a conceptual argument rather than to identify a statistically valid spread of the phenomenon studied, both samples were convenient in character. I solely conducted all the coding and analysis. Other methodological details are discussed in conjunction with each segment of the empirical investigation. After reporting on these, the article discusses possibilities for deeper theorizing of "information", which lie in IS research, informing science, and semiotics.

\section{Evaluation of Websites}

\section{Methods}

The first part of the investigation reported here was an evaluation of menus at Websites with respect to the manner in which the term "information" was cited. The Websites evaluated belonged to the domains of education, government, and travel industry (a domain of e-commerce). The geographical coverage was limited to Canada and Germany. The evaluation covered the levels of home page and one branch down. The deployed analytical methods were: (a) frequency assessment of the term "information", (b) semantic analysis (inferring the meaning of "information" within the given text), and (c) stakeholder-type analysis of intentions behind design choices. 


\section{A University Department's Website}

The first example studied belongs to educational domain. The University of Manitoba was conveniently chosen for this part of the study. This university maintains a sizeable Website that was radically redesigned about five years ago. The Website is actually a federation of Websites serving 24 departments (faculties) and programs, and various university operations (research, libraries, etc.). I refer to all these as "segments" of the university Website. The Website also serves as the access point to various documents and systems (e.g., students' records, online education, etc.). The content of the segments is maintained in a distributed fashion with adherence to some design rules that should engender the same "look and feel" across the site (e.g., the university banner, and the look and placement of menus, although not their wording).

The segment evaluated belongs to the university's department of management and its home page for the undergraduate program (http://umanitoba.ca/faculties/management/programs/undergraduate/index.html). The left hand-menu contains 12 items, including these: Important Information, Program Design, Admissions, Current Students, Fees \& Financial Assistance, Awards and Scholarships, Special Programs \& Services, International Student Information, and List of Majors. I underlined the items citing the term "information."

More occurrences of "information" loom at the menu level one step down from the item "Important Information". Guessing what is behind this item is likely to vary widely from money issues to notable dates and physical safety and navigation (the building of the concerned is surrounded by construction works deploying heavy equipment and transforming the local environ from day to day). The linked page, however, contains announcements that change over time. At the time of evaluation, some of the announcement headings were (underlining mine, capitals original): *NEW COURSE*, 2010 REGISTRATION INFORMATION SESSIONS, EVENING HOURS, UNDERGRADUATE OFFICE CLOSURE, and IMPORTANT REGISTRATION INFORMATION.

In evaluation, the menu in the undergraduate program home page contains the term "information" in two menu items. One may wonder, why is "information" added just to these items? Would not it fit well with some (if not all) others as well (e.g., Program Information, Fees Information, Admissions Information)? Why not be consistent? Or, since there is "International Student Information," why is "Current Students" left orphaned without the reassuring company of "information"? Since the space does not appear to be the reason, one can only hypothesize that the designer's arbitrary choices played a role. But one can also turn the question around to ask whether "information" is needed at all. If the term "Current Students" is understandable for visitors, would not "International Students" be equally sufficient? Furthermore, the branch down from the item "Important Information" leads to various contents (news, alerts, notices, declarations, other "information", etc.). Therefore, the term is not descriptive and may even create a confusing circular effect. This arbitrary variety of the referenced content triggers the question, is "information" the best word? Would the "announcements" fit more appropriately? Has the designer thought of alternative and descriptive wording?

Hypothesizing about the designer's thoughtfulness finally breaks down against the phrase "registration information sessions". It can be read as "sessions on registration information" (note the phrase "registration information" in the item "important registration information") or as "information sessions on registration." Therefore, the potential for confusion on the visitor side is significant. While abundantly citing "information", perhaps for the sake of raising the seriousness of the referenced content, the content designer - paradoxically - was rather sparing in other instances of naming. Note that the term "registration" is an orphan of the phrase "course registration", as if the latter should be as obvious to the clients as it is to the users of the given organizational lingo. A lack of concern for the client side is apparent. 


\section{The University Home Page}

The home page of The University of Manitoba's website (http://umanitoba.ca) is maintained by the university's IS department. The page contains a few dozens of menu items. There is a permanent menu area (e.g., Academic Life, On Campus, and Resources, totaling 19 items). In addition, there is a dynamic menu area that changes with a mouse hovering over the main menu items across the screen. Its categories include Future Students, Current Students, and Faculty \& Staff. These categories do not expand into drop-down sub-menus, as is the case in departmental segments of the Website (discussion above), but in the mentioned dynamic area. This solution saves the screen space for accommodating lengthy sub-menus (for example, the category Future Students contains 21 items). My evaluation of the home page reveals that the term "information" is cited three times - once in the permanent menu area ("Information for parents"), and twice in the dynamic area ("More future student info," and "More current student info").

In evaluation, it is apparent that "information" is used sparingly while the menus are understandable and the whole page reads quite well. Still, one may wonder whether the terms "information" and "info" could have been completely eliminated. Would not the phrase "For parents" be sufficiently understandable for referencing matters of interest to parents? Would not the phrase "Read more" or just "More" point clearly to the next page instead of "More... info"? (I leave to the reader to judge appropriateness of inscribing the colloquialism "info" right on the face of an institution that should teach proper English.) In spite of the transgressions, this Web page provides a stark contrast to the infomantra-plagued departmental site analyzed above.

\section{City Elections Website}

The second example is from the domain of electronic government (e-government) in Canada, the Winnipeg Elections Website (http://www.winnipeg.ca/clerks/docs/elections/2010election). The Website for elections in the city of Winnipeg, in Manitoba, Canada was updated in the fall 2010 in support to the elections for the city hall. The focus of my evaluation was on the main menu at the home page.

The home page's main menu is positioned across the upper part of the screen. The menu is brief, comprised of five items: Candidate Information, Voter Information, General Election Informa-

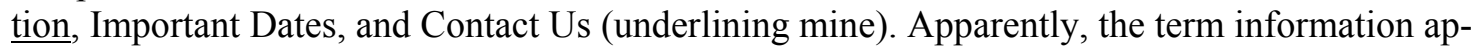
pears three times in the main menu. Descending one menu branch down reveals the menus that contain even more numerous instances of "information". The link "Candidate Information" triggers a menu where "information" appears in 5 of 11 items; "Voter Information" reveals two appearances of "information" out 12 items.

In evaluation, the term information is overused in this user interface. It appears 10 times in all the 46 menu items at the two menu levels analyzed, which is $22 \%$. While the informer may have had some reasons for loading the screens with "information", those reasons are not obvious to the client. Rather, the limited space of electronic screens appears unnecessarily cluttered and wasted as this loading does not contribute to semantic clarity. For example, instead of "Candidate Information," the label could read "For Candidates" or simply "Candidates." The same truncation without hampering understanding on the visitors' side can be applied to the items in the category "Candidate Information" which currently read as "Information for Major Candidates", "Information for Councillor Candidates", and so on.

\section{Federal Government Website}

In addition to the elections Website previously discussed, the other instance of e-government I investigated was the home page of the Canadian government's department called Citizenship and Immigration Canada (http://www.cic.gc.ca/english). The main menu is positioned along the left 
hand-edge of the home page. In a bit truncated form, the menu consisted of the following categories (shown on the left) and the belonging item-links (shown in parentheses):

The Department (About Us, The Minister, Media Centre)

Come to Canada (Visit, Work Temporarily, Study, Immigrate, Refugees)

Live in Canada (Before You Arrive, After You Arrive)

Citizenship (Apply for Citizenship, Celebrate Citizenship, Citizenship Judges)

Canadian Residents (Sponsor Your Family, Adopt a Child, Hire a Foreign Worker)

Resources (Publications, Application Forms and Guides, Research and Statistics)

In evaluation, the word "information" does not exist in this menu. It is not used in the associated menus either. This "information"-free wording is semantically legitimate as I have found that navigation on the site to be intuitive and easy. Semantically, the wording applied is superior to labeling any content as "information". The site visitor does not have to guess what "information"wording stands for since there is clear labeling of the associated coverage. For a mental test, the reader may try to imagine adding "information" to "The Department," "Citizenship," "Media," "Study," "Refugees," or to replace the category "Resources" with "Information." This wording would be in spirit of infomantra. Does adding "information" add any information?

A particular quality of this menu's language emanates from the action terms used (e.g., come, visit, work, live, apply, and sponsor). The visitor is inspired to actively investigate opportunities and conditions pertaining to immigration. The visitor is a subject or agent engaged in action of keen personal interest. In contrast, using the term "information" puts the visitor in a passive mode. Piles of information things are stored behind hypertext links, and the visitor is assumed to "take" the things rather than invited to investigate immigration opportunities and conditions. The action and observer models of user amount to different ontologies with which Web designers operate. The former is superior with regard to the informing effectiveness.

\section{European City's Tourist Website}

The dot-com part of the sample addressed the travel industry, partly because this industry has been a diligent promoter of the word "information" and partly for convenience reasons. The inscription "Tourist Information" has become so pervasive around the world, that one's mind is likely to fail if challenged to invent an alternative term (it appears that the term "tourist guide" has fallen into oblivion). For example, a search on "Berlin" (the capital of Germany) via the Google portal in the fall of 2010 resulted in hypertext links with the following accompanying descriptions (underlining mine):

- Berlin tourism and travel information such as accommodation, festivals, transport, maps, activities and attractions in Berlin...

- Berlin tourism information - accommodation, tickets, events, souvenir shop and further information for your stay in Berlin.

- Find general info on Berlin City Guide.

The Website evaluated indeed is associated with Berlin. It is called Mowitania Kulturplanung Berlin (http://www.ferienwohnung-zimmer-berlin.de/Tourismus Berlin/index en.htm). This is also the name of a tourist and travel agency in Berlin. After re-unification of the West and East Germany Berlin in 1991, this city has become one of major tourist attractions in Europe. Tourists' pressing need for learning about the city naturally parallels this trend. 
The main menu at the Mouwitania Website (underlining mine) is implemented as a column of headings and associated hypertext links on the right hand-edge of the home page. The menu headings/categories are (underlining mine): Helpful information, Accommodation/Travel, Tourism information, Interesting spots, Museums in Berlin, Events, Tourism agencies, Universities, Berlin city map. The category "Helpful information" references airports, "infomaterial + brochures", traffic, crime, city map (also existing as a separate menu segment), visas, important telephone numbers, etc.

At a menu branch down, the item "infomaterial" leads to a page entitled with "Order Information Berlin". The main portion of the page reads:

"You need information and brochures? This package costs 8,50 EURO including normal postage:

- (3 items citing travel guide, shopping guide, and city/public transport map - deleted)

- Information and prices of the public transport

- WelcomeCard-Flyer - information about the WelcomeCard

In evaluation, "information" is used excessively on the Mouwitania Website in an all-inclusive meaning. Instead of putting some effort in identifying a term that can refer to airports, traffic, crime, visas and other phenomena of general interest, the designer succumbed to the easy choice ("Helpful information"). The infomantra indicates a lazy man's choice, a handy wording that relieves designers from categorizing more precisely the associated data content. Interestingly, the neologism "infomaterial" may represent an attempt of using a more precise referencing to a particular object - publications for Berlin visitors.

However, the escape attempt ends where it started: the "info" term is inescapable pre-empting the cognitive space for creating optional terms (e.g., "tourist publications"). Plausibly for the same reason, "Helpful information" cannot be named with "Helps" or "Important". Even the somewhat self-referencing phrase "Important links" could be a more meaningful choice. As in the case of departmental Website and the city election site, the reasons for excluding "information" from certain menu items are as opaque as the reasons for including it. Why not say "Accommodation/Travel information", "Interesting spots information", or "Events information"? If the ears of visitors are attuned to infomantra, they might wonder if any information "is provided" behind those hypertext links without "information" in their name. Therefore, informer's choices are quite arbitrary.

\section{North American City's Tourist Website}

Another tourist industry Website evaluated supports the travel industry of the city of Montreal, one of the largest cities located in the province of Quebec in Canada. The Website belongs to Tourisme Montréal, a private, non-profit organization. Montreal has long been a popular tourist destination in North America and thus visitors' need for learning about the city are likely be significant as in the case of Berlin city discussed above.

The home page of this Website conveys instantly a professional look. In fact, there are six segments of the Website with partially overlapping content. These target different categories of visitors to Montreal, as stated on the Website - casual traveler, gay and lesbian, professional, and conference organizers. My evaluation applies to the traveler segment of the Website.

The main menu runs across the upper part of the home page and contains these categories: Montreal TV, Discover, Hotels and Booking, Cuisine, What To Do, Packages, Travel Information, and Blog (underlining mine). The category Travel Information leads to this sub-menu: Access, Getting Here, Getting Around, and FAQs (frequent answers and questions). There is also an auxiliary 
menu docked to the bottom of the screen. Its content is: MontréalCam, 中文网站 (in translation, "Chinese Website"), Montreal Irresistible, Contact Us, Site Map, Legal Notice, RSS Feeds, Newsletters, Our Partners, and About Us.

The term "information" does not appear in any sub-menu. However, it is used in the phrase "More info" that appears to be a preferable name for the hypertext links guiding users to the pages with descriptions of city attractions. In contrast, on other pages such links are also alternatively named as "Learn more", "Have a look", "More characteristics", "More types", and "Other neighbourhoods".

In evaluation, the term "information" is rare at the Tourisme Montréal Website. The wording of menu items is brief and denotes clearly the associated data content. Menu items are sometimes named in action terms which invite the visitor into the role of active explorer. A semblance of infomantra is found only in naming navigation links with "More info". But examples of better design are offered on this very same site, as in "Learn more", and "More characteristics". From a general perspective of Web menu design, "Learn more" reads as an appropriate replacement for "More information". Also, the phrase "More characteristics" (or whatever is adequate to couple with "more") is instructive as the unambiguous way of specifying the referenced content.

This inspires thinking of even more radical alternatives to the infomantra, such as abbreviating link names just to "More" and letting the user infer what content is referenced. Of course, the content must be as precisely organized as in the case of this Montreal Website.

In summary, the evaluation of menus of Websites in the educational, government, and commercial domain shows two contrasting designs. In one of these, the term "information" is pervasive, used in an all-inclusive fashion to refer to just about any content (including other "information"). While announcing that they "provide information", content designers may refer to various coverage that indeed is opaque to their clients. Coupling "information" with other terms appears arbitrary. Designers might assume that the suffix "information" increases the importance of the referenced content. Another possibility is that they simply invoke their organizational lingoes - inadvertently or otherwise. Reasons for exclusion of "information" are equally opaque. Therefore, in this informer-biased design, "information" is not very informing a term. Even the designers could feel that way when trying to introduce a more descriptive label, such as "infomaterial" (ironically, this attempt just re-enforces infomantra). Ontologically, this design assumes that information is a thing for consumption by a passive client. Whether informing really happens is out of consideration. Exposed to this design, the client can just cry out: "It's not information, stupid" (INIS)!

However, there is a contrasting design that can spare users from seeking shelter of the INIS principle. This design uses the term "information" sparingly or not at all. It prefers precise denotations of the referenced content genres. The language used demonstrates that the term "information" indeed is not necessary for naming menu items at Websites. Even the infomantra staple "For more information" is supplanted by effective alternative wording. Ontologically, this approach treats clients as agent that actively explores conditions, opportunities and procedures that Websites present. This design points to ways out of infomantra and informer bias.

\section{"Information" in Academic Literature}

\section{Methods}

In the second part the investigation, I analyzed how the word "information" is used in the academic literature. As in the Website investigation, the sample was convenient, drawn from empirical research published in information systems journals. For this investigation, I developed an analytical scheme based on the following questions. 
1. Is the term "information" cited in the article? This question served as the filtering criterion for the inclusion in the sample.

2. Is the term "information" used in a technical sense other than an object susceptible to manipulation, which can be collected, stored, retrieved, or provided? This criterion implied searching for an explicit definition of information. If no definition was stated, I examined statements containing the term information in order to grasp an implicit concept of it. For example, a conjunction of the terms "information" and "provision" would lead to the negative answer to this question.

3. Are both terms "information" and "data" used and clearly differentiated? The term "data" has to refer to the subject of research in connection with IS and not the outcome of data collection ("research data"). This criterion invited comparing the statements containing "information" or "data" to determine if these terms refer to different concepts. A negative conclusion, for example, would follow if "information" and "data" were used interchangeably for referring to a content collected, stored, retrieved, or provided.

The analytical process applied is represented as the decision tree depicted in Figure 1.

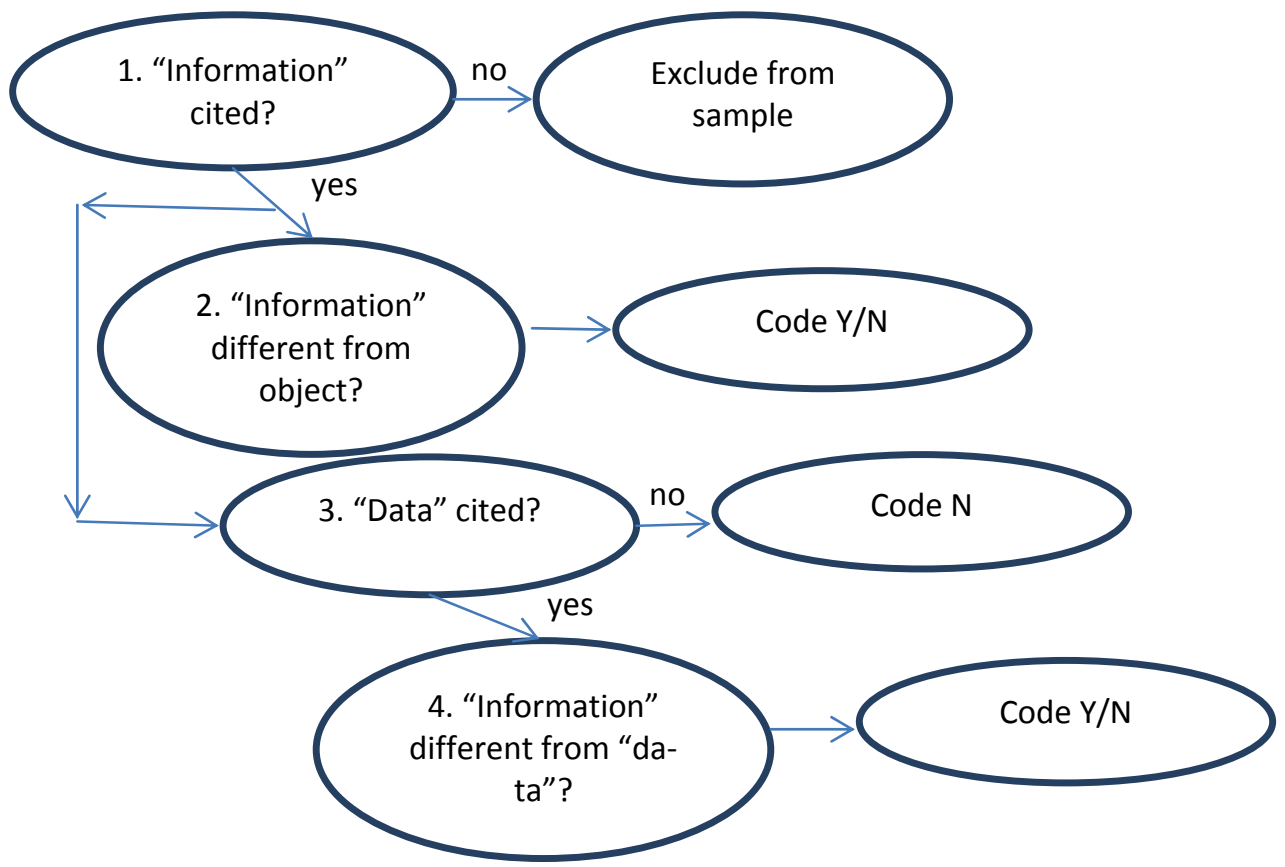

Figure 1. Decision Tree for Analytical Process

\section{Dominance of Reified "Information"}

The results of applying the above analytical scheme are shown in Table 1 . About $10 \%$ of the articles initially sampled were eliminated based at step 1 in the analytical process (see Figure 1) -- is the term "information" cited? Columns in Table 1 correspond to steps 2, 3 and 4 in Figure 1. Citations of phrases or sentences are verbatim. Articles cited in two rows use both terms "information" and "data" (these passed both steps 1 and 4). Steps 2 and 4 lead to no branching but to straight coding with a "Y" (yes) or "N" (no), depending on the finding.

As indicated in Table 1, most articles do not operate with a technical concept of information that is different from an object that can be manipulated in some way (note the " $\mathrm{N}$ " in column 1). This 
reified concept of information is often used in the IS literature. It is indicated by action terms, such as "provided, collected, stored, retrieved, given, and taken". Although the phrase "information sharing" may suggest thinking of information in terms of a cognitive process, this usually is not the case. Comparing this phrase with other phrases using "information" usually disqualifies such a possibility. An example is Article 11 in Table 1. A less straightforward example is instantiated in Article 10. The author uses genre categories to differentiate between information, knowledge, and "other resources." "Information" refers to system features and events, while "knowledge" refers to tips and procedures for the system use. Materials for users' training are "other resources." On the one hand, this approach is interesting for using distinctive genre categories rather than blanket referencing with the term "information". On the other hand, the discussion about "control of information" (i.e., recordable system features and events) as opposed to knowledge of system-related tips and procedures reveals that, for these authors, only knowledge is internal to cognition while information is not; therefore, it is akin to an object.

There are exceptional articles in which "information" is defined outside the mainstream concept. Examples are in articles 7 and 5. Both are rooted in the psychological perspective. Article 7 cites a behavioural concept of information, focused on perception and cognitive processing of perception. In Article 5, the author proposes a concept of information shape, which refers to spatial and semantic properties that convey coherence and can be exploited both semantically and physically to gather meaning (Dillon, 2000). For example, a user that navigates through electronic text displayed on the computer screen may be able to know where $\mathrm{s} / \mathrm{he}$ is, based on both semantic clues (the meaning of the therein recorded discussion) and location clues (e.g., headings and keywords). Previous knowledge makes a difference between users with regard to the creation of meaning aiding navigation.

Some articles use the term "data" in addition to "information" (note the code "Y" in column 2 of Table 1; also each of these articles is represented by two rows). Particularly interesting for this discussion is comparing the respective concepts to see if "information" is differentiated from "data" in some more substantial sense than that of "organized/meaningful" data (the code "Y" should be in all columns in Table 1). There is just one such instance in Table 1, article 13. The authors state the respective concepts and then apply them in a qualitative study.

Table 1. "Information" in IS Literature

\begin{tabular}{|c|c|c|c|c|}
\hline No & Citation & $\begin{array}{c}1 . \\
\mathbf{I}<>0\end{array}$ & $\begin{array}{l}2 . \\
\text { D }\end{array}$ & $\begin{array}{c}3 . \\
\mathbf{I}<>\mathbf{D}\end{array}$ \\
\hline \multirow[t]{2}{*}{1.} & $\begin{array}{l}\text { What is more, the flow of knowledge and information is also assumed to be en- } \\
\text { tirely one way. }\end{array}$ & \multirow[t]{2}{*}{$\mathrm{N}$} & \multirow[t]{2}{*}{$\mathrm{Y}$} & \multirow[t]{2}{*}{$\mathrm{N}$} \\
\hline & $\begin{array}{l}\text { distributed data systems; } \text { standards for sharing of data and knowledge } \\
\text { (Baskerville \& Myers, 2002) }\end{array}$ & & & \\
\hline 2. & $\begin{array}{l}\text { This could be achieved by automatically recommending to the sender the optimal } \\
\text { amount of context information in the message (Te'eni, 2001) }\end{array}$ & $\mathrm{N}$ & $\mathrm{N}$ & - \\
\hline \multirow[t]{2}{*}{3.} & $\begin{array}{l}\text { - Eighty-nine percent of those with active CRM deployments reported collecting } \\
\text { sales history data, whereas } 88 \% \text { gathered information about customers' service } \\
\text { requests. }\end{array}$ & \multirow[t]{2}{*}{$\mathrm{N}$} & \multirow[t]{2}{*}{$\mathrm{Y}$} & \multirow[t]{2}{*}{$\mathrm{N}$} \\
\hline & $\begin{array}{l}\text { - In U.S.A. enterprises, the main barriers are integration with legacy systems } \\
(65 \%) \text { and pulling together scattered legacy data sources }(62 \%) \text {. } \\
\text { - the marketing executives surveyed stated that they were collecting a wide range } \\
\text { of data about their customers. (Fedorowicz, Ray, \& Gogan, 2004) }\end{array}$ & & & \\
\hline 4. & $\begin{array}{l}\text { - Using information on the timing of technology releases, } \\
\text { - Using the information provided by these two cycles of technology evolution in } \\
\text { the Wi-Fi Ecosystem (Adomavicius, Bockstedt, Gupta, \& Kauffman, 2008) }\end{array}$ & $\mathrm{N}$ & $\mathrm{N}$ & - \\
\hline
\end{tabular}




\begin{tabular}{|c|c|c|c|c|}
\hline No & Citation & $\begin{array}{c}1 . \\
\mathbf{I}<>\mathbf{O}\end{array}$ & $\begin{array}{l}2 . \\
\text { D }\end{array}$ & $\begin{array}{c}3 . \\
\mathbf{I}<>\mathbf{D}\end{array}$ \\
\hline 5. & $\begin{array}{l}\text { - improving the design of information to convey meaning to specific user com- } \\
\text { munities (Dillon, 2000) }\end{array}$ & $\mathrm{Y}$ & $\mathrm{N}$ & - \\
\hline \multirow[t]{2}{*}{6.} & $\begin{array}{l}\text { - The information gathered covered the diverse requirements of the bank; } \\
\text { - tellers and telemarketers whom they had to consult were now equipped with } \\
\text { ready information from the CRM system }\end{array}$ & \multirow[t]{2}{*}{$\mathrm{N}$} & \multirow[t]{2}{*}{$\mathrm{Y}$} & \multirow[t]{2}{*}{$\mathrm{N}$} \\
\hline & $\begin{array}{l}\text { - the new system had different user interfaces and required different data process- } \\
\text { ing procedures; } \\
\text { - With the data (on customers), the project team devised clear CRM strategies } \\
\text { (Kim \& Pan, 2006) }\end{array}$ & & & \\
\hline 7. & $\begin{array}{l}\text { - Information derived through direct experience with the attitude object is likely to } \\
\text { result in the individual being more able to evaluate the object clearly and confi- } \\
\text { dently. } \\
\text { - direct experience may lead an individual to be more attentive to incoming be- } \\
\text { havioral information (Karahanna et al., 1999) }\end{array}$ & $\mathrm{Y}$ & $\mathrm{N}$ & - \\
\hline 8. & $\begin{array}{l}\text { - Corporate accounting had little formal organizational power and no independent } \\
\text { information to develop a system by means of which the necessary information } \\
\text { would flow directly; } \\
\text { - The raison d'etre of MIS is to provide managers with useful information; } \\
\text { - Information systems can be described and categorized in many ways: ...by type } \\
\text { of data (numbers, text, graphics, audio, video); } \\
\text { - A financial information system collects and summarizes financial data } \\
\text { - divisional accountants collected and stored transaction data; (Markus, } 1983 \text { ) }\end{array}$ & $\mathrm{N}$ & $\mathrm{Y}$ & $\mathrm{N}$ \\
\hline 9. & $\begin{array}{l}\text { - personal computers used primarily for storing and processing information within } \\
\text { a single organization. } \\
\text { - mutual exchange of information, and joint problem solving; (Melville, Kraemer, } \\
\text { \& Gurbaxani, 2004) }\end{array}$ & $\mathrm{N}$ & $\mathrm{N}$ & - \\
\hline 10. & $\begin{array}{l}\text { - we conceptualize valued network density and valued network centrality, both of } \\
\text { which take into account ties to those with relevant system-related information, } \\
\text { knowledge, and resources; } \\
\text { - This refers to the connectedness of a focal employee to others, weighted by the } \\
\text { perceived strength of the tie and the alter's control of system-related information } \\
\text { (such as system features, upcoming releases, demo dates), knowledge (such as tips } \\
\text { and tricks, short-cuts, process sequences), and other tangible resources (such as } \\
\text { training resources, manuals, tutorials) (Sykes, Venkatesh, \& Gosain, 2009) }\end{array}$ & $\mathrm{N}$ & $\mathrm{N}$ & - \\
\hline 11. & $\begin{array}{l}\text { - The use of IT altered the nature and quality of information shared by the partici- } \\
\text { pants; } \\
\text { - As a gatekeeper, the broker gathers information from a third party and manipu- } \\
\text { lates it (Schultze \& Orlikowski, 2004) }\end{array}$ & $\mathrm{N}$ & $\mathrm{N}$ & - \\
\hline 12. & $\begin{array}{l}\text { - We also had access to Adweb's Intranet (internal website), where procedural, } \\
\text { organizational, and technical information was posted. } \\
\text { - This constant inflow of new (often ambiguous) information } \\
\text { kowski, \& Yates, 2006) }\end{array}$ & $\mathrm{N}$ & $\mathrm{N}$ & - \\
\hline 13. & $\begin{array}{l}\text { - data about different phenomena in an organization (e.g., about products, custom- } \\
\text { ers, prices, etc.) might be stored on paper or in information systems (IS), but it is } \\
\text { only when these data are placed in a context and interpreted by someone that data } \\
\text { become meaningful information. (Axelsson \& Goldkuhl, 2010) }\end{array}$ & $\mathrm{Y}$ & $\mathrm{Y}$ & $\mathrm{Y}$ \\
\hline \multirow[t]{2}{*}{14.} & $\begin{array}{l}\text { - Software enables each party to access the other's data } \\
\text { - the largest companies may face technical capacity constraints that prevent full } \\
\text { data integration (Markus \& Tanis,2000) }\end{array}$ & \multirow[t]{2}{*}{$\mathrm{N}$} & \multirow[t]{2}{*}{$\mathrm{Y}$} & \multirow[t]{2}{*}{$\mathrm{N}$} \\
\hline & $\begin{array}{l}\text { As a result, combining information about sales or manufacturing with accounting } \\
\text { data was difficult and error prone. (Markus \& Tanis, 2000) }\end{array}$ & & & \\
\hline
\end{tabular}

Note: $\mathrm{I}<>\mathrm{O}=$ information not an object; $\mathrm{D}=$ data; $\mathrm{I}<>\mathrm{D}=$ information not same as data; 
In summary, the empirical academic literature analyzed exhibits a split: in one segment of it, researchers rarely state what they mean by "information" but rather draw on an implicit weakly formalized premise that information is the data organized by computer. In another literature segment, the authors offer innovative, more formal conceptualizations of information. This split resembles the one from the domain of Web design, where some sites exhibit infomantra and others refrain from it. In the literature assuming that information is organized data, "information" appears to be conceived as an object that can be manipulated and passed among people and between people and IS. This reified information is not clearly differentiated from data (another object). This reified concept of "information" in the empirical academic literature is similar to the one that generates infomantra in Web design.

\section{Conceptualizations of Information}

There is a conceptual academic literature that concentrates on studying "information". Almost thirty years ago, Machlup and Mansfield (1983) published a unique academic project that was to illuminate relationships between concepts of information in different disciplines. The initiator of the project, Fritz Machlup, gathered prominent authors of the time from the areas of linguistics, library and information science, cognitive science, social sciences, computer science, informatics, cybernetics, information theory, systems theory, and some others "concerned with information". The list of disciplines claiming interest in "information" contained several dozens of entries, including some peculiarly sounding today (e.g., informatology, informology, and informantics). A hope of producing groundwork for a meta-science to be called "information science" can be identified behind this project. Although he died before his 743 page volume was published, Machlup did manage to write the Epilogue based on all the contributions.

In Epilogue, Machlup defined information in terms of (a) the telling of something and (b) that which is being told (Machlup, 1983, p. 642). Borrowed from the Oxford English Dictionary, this definition focused on the process of human communication and on its content (the message). The definition filtered out into a list of "metaphors" all the concepts of information outside the domains of human communication, cognition, and semiotics. For example, "metaphoric" concepts of information were those used in genetics, biology, cybernetics, computers, communication technology (the famous mathematical model of communication by Shannon \& Weaver,1949), technology in general (since only people can do the telling), and in physics. It was not clear whether this project was indeed appreciated as a contribution toward a generic concept of information. One can identify indications of uncertainty in this respect in both Machlup's Epilogue and in Introduction written by the co-author Mansfield after Machlup's death.

Three decades after, a unifying concept of information is as far from reach as ever. Information science has not become a unifying field for study of information. Instead, new terms and frameworks with integrationist aspirations have emerged, such as informing science and social informatics. Nevertheless, disciplinary boundaries in study of information have been preserved and some new boundaries have been created. One is the field of IS (or Management Information Systems). Not only that a cross-disciplinary concept of information has never emerged, but it is un-

clear - as I argue in this article - what "information" is precisely supposed to mean in a particular discipline. Moreover, we witness a new problem of differentiating between data and information, as in the statement "information is organized data".

Machlup himself inclined to dismiss the topic of data as an import from the vocabulary of "computer systems". This was consistent with the dictionary definition Machlup used since computer could not "tell" anything essentially different than what was put into it. Computer input, what is processed in computer, as well as output in its various states of organization - Machlup saw all these as instances of data. It made no difference for a computer user if the computer output was called "data" or "information". Determined a writer he was, Machlup argued that the notion of 
"data" was unimportant even from a general perspective: "we have information" or "we have data" is the same, and "there is no need to establish either a hierarchy or a temporal sequence in discussing data and information" (Machlup, 1983, p. 648). But being also broad-based thinker, Machlup could not help it but offer, in the same breadth, refutations of the data-information equation. He acknowledged that it was sensible to say "our data do not furnish the information wanted in this case". He also cited Tiechroew's (1978 as cited in Machlup, 1983, p. 648) crisp thought: "sometimes a distinction is made between the mechanistic representation of the symbols, which is called 'data,' and the meaning attributed to the symbols, which is called 'information'." In fact, Machlup marked a controversy that extends to date.

\section{Meaningfulness Out of Organization}

Many definitions of information in the IS literature relate information and data. Knox (2009) has surveyed definitions of information, data, and knowledge. Here are several typical definitions from his survey:

- "information is data endowed with relevance and purpose" (Drucker, 1989);

- information is "organized data, meaningful and contextually relevant... used in decision making" (Chaffey \& Wood, 2005);

- "information represents data arranged in a meaningful pattern" (Hislop, 2005);

- information is data that has been processed into a form that is meaningful to the recipient, and is of value in decision making.

The term "data" in these definitions is usually referred to "business facts" such as customer, product, and cost. Indeed, all the definitions belong to a common type that is implicit in most of the academic articles discussed above. Therefore, information is thought of in terms of a thing that can be provided, stored, exchanged, and so on. If data are susceptible to the same manipulation methods, it follows that these methods do not constitute a basis for differentiating between data and information. What does?

All the definitions cited above operate with some transformation function that is supposed to cause data to metamorphose into information (endowing, organizing, arranging, and processing). But one can search in vain the literature for formal definitions of these terms, let alone a corresponding metric. The authors usually do not go beyond providing examples. Moreover, some terms resemble metaphors (e.g., "endowing"). Still, this fact has not made them even a bit less attractive to textbook writers (Drucker's definition is common to IS course materials in business schools). In contrast, the terms "organization" and "arrangement" are more formal in appearance. Still, it remains opaque what is that breadth and/or depth of data organization (arrangement) that transforms data into information.

Data can be organized in many ways. The simplest organization of recorded data is spatial, such as putting letters next to each other to form words. Is single word information? Or it is minimally a phrase, or a sentence? Here is an organization of letters: gwybodaeth. Does it constitute an instance of information? Another sort of data organization is morphological: numbers are grouped together, as opposed to pieces of text, as opposed to graphical data, etc. Is this level of organization sufficient for making data into information? Or do data also need to be organized according to the subject they refer to? For example, the words that signify customer names are grouped together as opposed to words signifying customer account managers. Or perhaps one has to apply even a higher level of organization to create information. For example, text, numbers and graphs are arranged into a management report, which represents a "meaningful pattern" and, in turn, renders the constituent pieces to information? This is where the "processing" (by computer) would enact the transformation function. 
What level and kind of organization indeed is necessary for emergence of information from data? This question is typically not addressed beyond the notion of document type. For example, an invoice or customer order is specific document types, each having predefined, named segments (usually called metadata). The invoice metadata constitute a structure for the invoice document. Most of documentation supporting daily operations, reporting, and planning in today's business follows predefined forms. Researchers have attempted to impose organization on more fluid data content as well. One such approach builds on speech act theory applied to design of email systems (Winograd \& Flores, 1986). The concept of promise, assertion, or some other speech act serves as a filter for organizing the content of message. Study of communication genres draws on a similar idea (Orlikowski \& Yates, 1994; Päivärinta, 2001). The announcement, opinion request, training manual, training evaluation, or some other genre provides a category into which organizational communication or documentation can fit.

The research on data organization forms represents a contribution in theorizing information. It may serve as a theoretical grounding for the effective Web design that uses descriptive labeling of the referenced content, which was discussed above. Still, the cited forms necessitate an educated client who will understand the concepts behind metadata. In addition, even if the organizational forms and educated client are in place, there is no guarantee that the client will be informed. If information is something that informs the client's cognition, then without considering the client side one cannot conclude that organized data make such an effect. Therefore, the transformation of data into information remains a hypothesis rather than an established cause-effect model. As Machlup (1983) hinted long ago: People selling management information systems "feel better if they call the output of their system information, that is, something of a higher order" (p. 648). However, it is apparent that attempts to differentiate such a "higher order" and a supposed lower order of data have, at best, been rudimentary.

Another common definitional aspect of information is teleological - information is associated with a purpose, and frequently with decision making. It is not always clear if the organization and purpose aspects are cumulative. If they are, it could be assumed that the purpose sheds a particular light on data, so that data are interpreted differently depending on different purposes. This theoretically resourceful idea, however, is far from implementation in IS research. It is also to be noted that the emphasis on decision making as the primary purpose of information filters out large domains of informing in organizations. Take managers, for an example. In addition to being decision makers, managers carry out other roles that have to do much with informing but little with decision making. For example, Mintzberg (1979) posited such roles as monitor, disseminator (of news, etc.), spokesperson, leader, figurehead, and liaison. If the same data are used for decision making and for other purposes, does a difference in purposes make a difference in information?

The final common characteristic to the definitions of information analyzed is the aspect of meaningfulness. It is usually assumed that to a client, such as decision maker, data become meaningful after being organized/processed. The implied premise is that meaningfulness is a consequence (an effect) of the organization and purpose of data (the causes). In all the three approaches to data organization discussed above, specified is the category or background of data. The document type approach also specifies the structure of a dataset (metadata). As the client's mind is focused on a relevant context, these data organizations may ease understanding a meaning of the data. However, it is unclear what or where the test of meaningfulness enters the assumed model? Who is to judge if the organized data put in a context "have a meaning" for the client? A sensible answer would be, as already mentioned, the client; alternatively, this could be an objective tester of the client's cognition. The puzzling "gwybodaeth" is not meaningful to most readers of this article. What else is needed to understand the meaning of this word? This question calls for completing the model, which the discussion in the next section addresses. 
In summary, the definitions of information provided in the mainstream, conceptual IS research usually comply with the reified concept pervading the IS literature. Differences between information and data are not clear in these definitions. Data "become meaningful" after being submitted to some sort of organization and processing, but the notions of organization and processing are typically not formalized beyond the content categorizing and metadata specification (the approaches of document type, speech acts, and communication genres). Whether the meaning is really invoked in the client's mind is the problem that is neither theorized nor investigated. It is also unclear what the meaning is about. If "business facts" are already meaningful, then their connections are supposed to create some higher order meaning. Which one, it remains unaddressed. In spite of advances over the lose notion of information behind Web site design, the concept of information in this academic literature still resonates with the infomantra and reinforces the INIS principle.

\section{Escaping Infomantra: Information is (about) Meaning}

One stream in the conceptual academic literature offers definitions of information that shift the focus to the meaning creation on the client's side. As early as in the 1960s, Swedish computer scientist Börje Langefors conceived information as a phenomenon internal to cognition and closely related to knowledge. In contrast, data are not information but can only represent information (see Bednar \& Welch, 2009). Put another way, information is a function of interpreting data, based on the person's knowledge and the time available for the interpretation (see Iivari \& Lyytinen, 1999). Consequently, information-related requirements concerning an IS cannot be equalized with their implementation in a data system. Langefors called the former "infological" problems and the latter "datalogical" problems.

A number of researchers in Knox's (2009) survey of definitions of information do associate information with meaning. For example, Boland's (1987) definition explicitly denies the reified concept of information as a resource or commodity that could be stockpiled as other factors of production. The author posits that information is meaning (cf. Knox, 2009, p. 155). Interestingly, Boland insists that the meaning can only be achieved through dialogue in a human community. This boundary condition resembles Machlup's (1983) notion of information as "the act of telling and that which is being told" (see the discussion above). Many advocates of the meaning approach contend that information has meaning, where the meaning is assigned by human agency (e.g., Davenport \& Prusak, 1998). Knox also supports the meaning-centered approach to information, which he labels "process view". He proposes a model in which data, knowledge, and information are interrelated, while human is in the role of "ascribing meaning, interpretation, and understanding" (Knox, 2009, p. 152).

From the perspective of the information view of organization (IVO), the term "information" designates a cognitive artefact that takes the forms of data, meaning, knowledge, and wisdom (Travica, 2005). There is interdependence between these forms. Data are defined in terms of sensual stimuli (e.g., visual, audio, and other stimuli) and symbols created for human communication (e.g., letters, numbers, sounds, etc.). Data have no meaning in themselves, but the meaning is attributed through a process of interpreting data in the mind of a knowing subject. Knowledge intervenes importantly in this process. Only data can be externalized, provided, exchanged, retrieved, while other forms of information are internal to cognition. To emphasize where the character of information is, IVO treats meaning as "information in a narrow sense". I admit that this labeling is a compromise between the intended focus (information as meaning) and widespread lingoes that rarely cite "meaning".

Kettinger and $\mathrm{Li}$ (2010) also build on Langefors's ideas to propose a knowledge-based theory of information (KBTI) that conceptualizes information in terms of a joint function of data and knowledge. Data refer to the measurement or description of states, and knowledge outlines the relation- 
ship between concepts underlying those states. Information is generated from the interaction between the states measured in data and their relationship with future states predicted in knowledge. Different kinds of IS are conceptualized as the embodiments of knowledge domains that are capable of transforming specific categories of data into information for business operations and decision-making. The authors use the label "value chain model of information" for signifying what in this article is called "reified concept of information". For them, the main reason for discrediting that model is that it cannot explain variation in information that is created from the same data. According to KBTI, knowledge makes that difference. From a critical distance, KBTI advances understanding of the role of knowledge in information creation, but it lacks clarity regarding the locus of meaning. Since no distinction is made between "information" and "information statement" (or "knowledge" and "knowledge statement") it appears that both concepts are conceived as external to the client's cognition. If information is meaning, as the authors postulate, it follows that meaning resides outside of cognition. Consequently, KBTI does not part with the "thingness" implied in the reified concept of information and the associated informer bias.

For the closure, here is a lexical concept of information that, as in Machlup's time, appears again more appropriate than the mainstream academic counterpart. According to the Webster Dictionary (2010), information is: (1) the communication or reception of knowledge or intelligence; (2) knowledge obtained from investigation, study, or instruction; (3) something (as a message, experimental data, or a picture) which justifies change in a construct (as a plan or theory) that represents physical or mental experience or another construct; (4) the act of informing against a person; and (5) intelligence, news; (and some more).

In summary, there is agreement among the authors cited in this section that information is meaning. This concept is in a stark contrast with viewing information as "organized and meaningful data", which takes meaning as a given. In contrast, the meaning-focused view relates data with knowledge and focuses on the process of information construction. The knowing subject is agency actively encountering data rather than passively consuming information as the object "provided".

\section{Fast Forward into the Past: Semiotics}

While the meaning-focused view exposes weaknesses of the mainstream thinking of information, it opens up a new question: What is meaning? The cited works of Langefors and of Kettinger and Li point to a relational character of information involving knowledge and data. Building on this assumption, I will use select ideas from semiotics in order to propose a concept of meaning.

One way of thinking about meaning is through examining relationships between symbols (data in various states of organization) and knowledge needed to interpret the data. This is in accord with Langefors and other akin theorizing cited in the preceding section. To understand the mysterious word "gwybodaeth" one needs to know Gaelic language. Knowledge is crucial in creating meaning in mind even in a more elementary way: one needs to know the Latin alphabet and how to read (e.g., the learned skill of producing voices, and the left-to-right rule of reading English). In addition, I presume that the discipline of semiotics constitutes substantial theoretical grounding for study of meaning, that is, information.

Semiotics (or semiology) was developed in the second half of the $19^{\text {th }}$ and the early $20^{\text {th }}$ century by American philosopher Charles S. Peirce and Swiss linguist Ferdinand de Saussure. Semiotics keeps developing as a discipline on its own, while influencing some other disciplines such as human communication theory. Theorizing independently from each other, Pierce and Saussure developed different semiotics that can be just very roughly sketched for the purposes of this discussion. 
Pierce was interested in the relationships between sign - say, a word - a physical object the word signifies, and the user's understanding of the relationship between the word and the object - the representant. The representant is central to the notion of meaning since the meaning of a sign is manifest in its interpretation (Peirce's theory of signs, 2010). (Note that students of semiotics may use the term sign to refer to all the three concepts, and thus semiotics is defined as study of signs or of the production of meaning via signification.) In contrast, Saussure's semiotics does not address physical objects. Rather, it is focused on the relationship between signifier (symbol) and signified (its interpretation). Saussure's assumption is that the relationship between signifier and signified is dynamic. In other words, meaning of signs emerges from relationships with other signs rather than objects. For example, meaning of words emerges from the manner in which words relate in a particular text. Figure 1 depicts basic concepts of these two semiotics and indicates their correspondence at a basic logical level.

Pierce's representant and Saussure's signified approximate the domain of mind or knowledge. Knowledge can be thought of in terms of concepts and their relationships. Pierce's object remains a helpful analytical element although other concepts may influence meaning more than object, as Saussure's assumed. These modifications are depicted in Figure 2. For example, the dog-object is signified by the dog-word or some other kind of data (picture, video). Dog-word and dog-object can conjure up dog-knowledge in human mind. Dog-knowledge could be thought of as a conceptual map consisted of a mental image of dog, the concepts of sniffing, barking, biting, danger, security, help, friendship, memory episodes involving physical dogs, mundane and technical definitions of dog, notions of beauty, strength, and so on. Dog-knowledge varies across individuals.

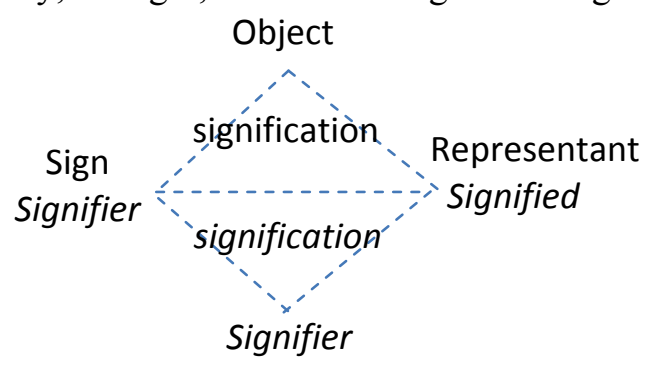

Figure 1. Basic Semiotic Concepts

Note: Pierce's elements are in normal print and Saussure's are in italics

For an alternative example closer to Saussure's semiotics one can take any of the less tangible concepts of dog-object, such as danger. There exists no single physical danger-object. Rather, a child learns through experience and rules, for example, that fire-object is dangerous. Rules taught engender directly definitional concepts in the learner's mind. Over time, other objects get signified with the danger-word, as the conceptual map of danger-knowledge grows. So for example, it may include hunger, disobedience to authority, war, toxic securities, terrorism... and each of these concepts may refer to both other concepts and to some phenomena in physical reality. Eventually, a generic definition of danger may emerge at the nexus of danger-knowledge. It, then, becomes the lens through which new objects in physical reality are signified with the danger-word and mentally abstracted into danger-knowledge. Those new danger-objects are signified by their own words that, in turn, draw the meaning from their relationship with the danger-word.

The two examples discussed represent informing processes or instances of inductive and deductive learning. The construction and interpretation of meaning is what information is. Information is apparently closely related to knowledge by both engendering it and being engendered by it. Drawing on these ideas, meaning, and therefore information, can be defined in terms of the process and product of interaction between data and knowledge, which take place in mind (Figure 2). Locating meaning in mind contrasts this concept from the mainstream concept of information 
criticized in this article. One implication of this distinction is that the test of information/meaning can be done just on the client side, given the input data and indications of the information creation on the client side.

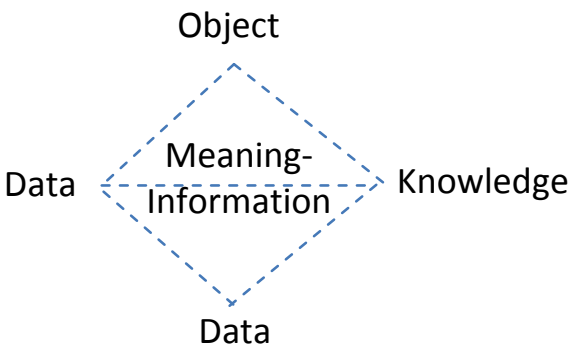

Figure 2. Semiotic Concepts in the Information Framework

In summary, semiotics provides a basis for understanding meaning, that is, information in terms of a process and product involving interaction between data, knowledge, and object, which takes place in the client's cognition.

\section{Summary and Conclusion}

The research problem of the presented study was the excessive use of the term "information" (infomantra) and its antecedents. The theoretical argument was supported by (1) an evaluation of menus at select Websites and (2) a review of select academic literature. Analysis identified that the term "information" is often used without a clear meaning, arbitrarily, as a common reference to any content that is supposed to inform or be communicated. From the client perspective, "information" used in this manner is not informing. The larger the infomantra, the wider the range of objects and concepts that are referenced by "information". If information means different things to different people, the effectiveness of informing and communication suffers.

The discussion identified a reified concept of information in the background of the infomantra. Information is objectified into a thing that can be provided, collected, stored, exchanged, instantly used, and otherwise manipulated. This reified information is not clearly differentiated from the notion of "data". As the analysis of conceptual and empirical academic literature has shown, data are assumed to become "meaningful" after being organized and/or computer-processed. However, a formalization of both data organization and meaningfulness is still lacking, in spite of contributions to the data organization research (speech acts, communication genres, document classification). Indeed, meaning aspects are typically circumvented. Juxtaposed to reified information is a meaning-focused view of information which some researchers advocate (Axelsson \& Goldkuhl, 2010; Boland, 1987; Dillon, 2000; Langefors as cited in Bednar \& Welch, 2009, and in Iivari \& Lyytinen, 1999; Kettinger \& Li, 2010; Knox, 2009). Premises from this research intersected with ideas from semiotics led to conceptualizing information as the meaning that occurs internally in the client's cognition. This conceptualization rejects reified information and renders the informerdeclared information content to the rubric of data.

It also follows from the presented discussion that the reified information can be associated with an ultimate antecedent of informer bias. The informer bias approach arbitrarily includes or excludes "information" in/from phrases inscribed on Web sites or in academic literature, rejects seeking more descriptive wording, tacitly assigns arbitrary meanings to "information", and makes unwarranted assumptions of informing effects on the client side. The informer in this tradition extends organizational lingoes without concern for the client and succumbs to intellectual inertia. The client is viewed as a passive consumer of reified information. The aspects explaining the in- 
former bias approach and discussed in this article are summarized in Table 2. The relationships between informer bias and its consequences can be modeled as a causal chain: informer bias $\rightarrow$ reified information $\rightarrow$ infomantra.

Table 2. Approaches to Informing

\begin{tabular}{|l|l|l|}
\hline \multirow{2}{*}{ Aspect } & \multicolumn{2}{c|}{ Approach to Informing } \\
\cline { 2 - 3 } & \multicolumn{1}{|c|}{ Informer Bias } & \multicolumn{1}{c|}{ Balanced } \\
\hline Term "information" & Excessive use & $\begin{array}{l}\text { Lower use; } \\
\text { Optional descriptive wording }\end{array}$ \\
\hline Concept of information & $\begin{array}{l}\text { Arbitrary to weak definitions; } \\
\text { Often tacit; } \\
\text { Reified; } \\
\text { Akin to data }\end{array}$ & $\begin{array}{l}\text { Formal definitions; } \\
\text { Various conceptualizations; } \\
\text { Differentiation from data attempted }\end{array}$ \\
\hline Client Ontology & $\begin{array}{l}\text { Out of scope; } \\
\text { Passive, consumes "provided" mean- } \\
\text { ing; } \\
\text { Meaning test unnecessary }\end{array}$ & $\begin{array}{l}\text { Within the scope; } \\
\text { Active, creates meaning in own } \\
\text { mind; } \\
\text { Meaning test uncertain }\end{array}$ \\
\hline
\end{tabular}

In the dominant culture of informer-biased use of "information", invoking the INIS principle appears the only defense at the client's disposal. But there are exits from the infomantra impasse. Web sites whose menus are entirely or nearly free of infomantra have been identified in this study. Even the seemingly proverbial "For more information..." is not a must as the designers created precise denotations of the referenced data content. In this design, the client is treated as agent invited to explore Website contents and possibly learn. Similarly, a part of academic literature offers original definitions of information and takes a meaning-focused view of information. It explores the relationship between data and knowledge and the process of information construction. These characteristics are summarized in Table 2 under the rubric of Balanced Approach to Informing. I argued that this line of inquiry should be continued, and extended analysis with some basic semiotic ideas, modified to accommodate the framework consisting of data, information and knowledge. This argument resulted in proposing that information refers to the process and product of interaction between data and knowledge, which take place in mind.

A theoretical implication of this study is that the concept of information should be revisited by concerned researchers. Information should be theorized in richer terms by drawing on the perspective of meaning. Empirical research in the area of IS and informing science needs to account for the enhanced understanding of information. If information is internal to cognition and its test has to be performed on the client's side, this means that research needs to focus on indications of informing, which lie in the cognitive and behavioral domain (note that the meaning test was remarked as uncertain in Table 2). As meaning is not susceptible to direct examination, it belongs to the domain of black box. This view is cognate to the standard psychological approach. Apparently, such an approach is quite challenging and demanding, inviting creative, new research. To track it solidly, more research is also needed to validate and explain in more details the causal chain - informer bias $\rightarrow$ reified information $\rightarrow$ infomantra.

Another implication has both theoretical and practical facets. If information-meaning is internal to the client's cognition, it follows that "information" should be replaced by "data" wherever the informer the informer cites "information". But such a change could shake up self-confidence of academics and practitioners alike. Web designers are likely to be affected, while IS marketers are seriously challenged. Imagine the lackluster slogans: "Data for new students", "For more data", or "Data at your fingertips". While being technically correct, this change might lead to massive 
brand depreciation in the eyes of a customer base accustomed to infomantra. Therefore, new and creative marketing approaches are needed to communicate the value of IS.

From the practical perspective, the implication of this article is that the right linguistic change would not be to replace the infomantra by a datamantra. While using "data" and "information" in academic literature is technically appropriate, Web content designers would improve their work if they follow examples of the successful Websites presented in this discussion that have no need for either term but use effective genre-based labeling of the informing content.

\section{References}

Adomavicius, G, Bockstedt, J. C, Gupta, A., \& Kauffman, R. J. (2008). Making sense of technology trends in the information technology landscape: A design science approach. MIS Quarterly, 32(4), 779-809.

Axelsson, A., \& Goldkuhl, G. (2010). Four tactics of establishing and preserving data stability. Journal of Information, Information Technology, and Organizations, 5, 67-84. Retrieved from http://www.jiito.org/articles/JIITOv5p067-084Axelsson422.pdf

Baskerville, R., \& Myers, M. (2002). Information systems as a reference discipline. MIS Quarterly, 26(1), $1-14$.

Bednar, P. M. \& Welch, C. (2009). Inquiry into informing systems: Critical systemic thinking in practice. In T. G. Gill \& E. Cohen (Eds.), Foundations of informing science: 1999-2008 (pp. 459-502). Santa Rosa, CA: Informing Science Press.

Boland, R. (1987). The in-formation of information systems. In R. Boland \& R. Hirschheim (Eds.), Critical issues in information systems research (pp. 363-379). Chichester: John Wiley \& Sons.

Chaffey, D., \& Wood, S. (2005). Business information management: Improving performance using information systems. Harlow, Prentice Hall, Pearson Education Limited.

Davenport, T. H., \& Prusak, L. (1998). Working knowledge: How organizations manage what they know. Cambridge, MA: Harvard Business School Press.

Dillon, A. (2000). Spatial-semantics: How users derive shape from information space. Journal of American Society for Information Science, 51(6), 521-528.

Drucker, P. F. (1989). The new realities. Heinemann.

Fedorowicz, J., Ray, A., \& Gogan, J. (2004). The ecology of interorganizational information sharing. Journal of International Technology and Information Management, 13(2), 73-85.

Hislop, D. (2005). Knowledge management in organisations: A critical introduction. Oxford, Oxford University Press.

Iivary, J., \& Lyytinen, K.. (1999). Research on information systems development in Scandinavia: Unity in plurality. In W. Currie \& B. Galliers, Rethinking management information systems (pp. 57-100). Oxford: University Press.

Karahana, E., Straub, D., \& Chervany, N. (1999). Information technology adoption across time: A crosssectional comparison of pre-adoption and post-adoption beliefs. MIS Quarterly, 23(2), 183-213.

Kellogg, K., Orlikowski, W., \& Yates, J. (2006). Life in the trading zone: Structuring coordination across boundaries in postbureaucratic organizations. Organization Science, 17(1), 22-46.

Kettinger, W. J., \& Li, Y. (2010). The infological equation extended. European Journal of Information Systems, 19, 409-421.

Kim, H., \& Pan, S. (2006). Information systems implementation: The case of customer relationship management (CRM). The DATA BASE for Advances in Information Systems, 37(1), 59-76

Knox, K. (2009). Information and informing science. In T. G. Gill \& E. Cohen. (Eds.), in Foundations of informing science: 1999-2008 (pp. 135-158). Santa Rosa, CA: Informing Science Press. 
Machlup, F. (1983). Semantic quirks in study of information. In F. Machlup \& U. Mansfield (Eds.), The study of information: Interdisciplinary messages (pp. 641-671). New York: John Wiley \& Sons.

Machlup, F., \& Mansfield, U. (Eds.). (1983). The study of information: Interdisciplinary messages. New York: John Wiley \& Sons.

Markus, M. L. (1983). Power, politics, and MIS implementation. Communications of the ACM, 26(6), 430444.

Markus, M. L., \& Tanis, C. (2000). The enterprise systems experience: From adoption to success. In R.W. Zmud (Ed.), Framing the domains of IT research: Glimpsing the future through the past (pp. 173-205). Cincinnati, OH: Pinnaflex Educational Resources.

Melville, N., Kraemer, K., \& Gurbaxani, V. (2004). Review: IT and organizational performance: An intergrative model of IT business performance. MIS Quarterly, 28(2), 283-322.

Mintzberg, H. (1979). The Structuring of Organizations: A Synthesis of the Research. Englewood Cliffs: Prentice Hall.

Orlikowski, W.J., \& Yates, J. (1994). Genre repertoire: The structuring of communicative practices in organizations. Administrative Science Quarterly, 39(4), 541-574.

Päivärinta, T. (2001). The concept of genre within the critical approach to information systems development. Information \& Organization, 11(3), 207-234.

Peirce's theory of signs. (2010). Stanford Encyclopedia of Philosophy. Available: http://plato.stanford.edu/entries/peirce-semiotics/\#SigEleSig

Schultze, U., \& Orlikowski, W. (2004). A practice perspective on technology-mediated n Relations. Information Systems Research, 15(1), 87-106.

Shannon, C.E., \& Weaver, W. (1949). The mathematical theory of communication . ( ed.). Urbana: University of Illinois Press.

Sykes, T. A., Venkatesh, V., \& Gosain, S. (2009). Model of acceptance with peer support. MIS Quarterly, 33(2), 373-393.

Te'eni, D. (2001). Review: A cognitive-effective model of organizational communication for Designing IT. MIS Quarterly, 25(2), 251-312.

Travica, B. (2005). Information view of organization. Journal of International Technology and Information Management, 14(3), 2005, 1-20.

Webster Dictionary. (2010). Available: http://www.merriamwebster.com/dictionary/information?show $=0 \& \mathrm{t}=1291088839$

Winograd, T., \& Flores, F. (1986). Understanding computers and cognition: A new foundation for design. Norwood, NJ: Ablex.

\section{Biography}

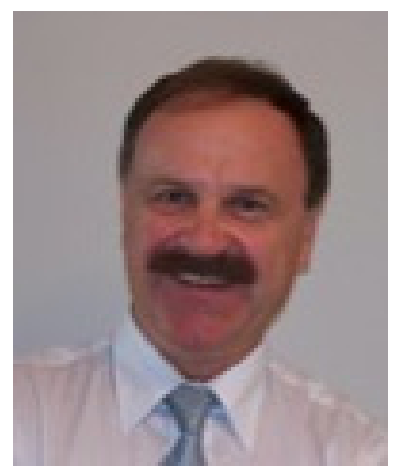

Bob Travica teaches information systems at the University of Manitoba in Canada, and investigates organizations from the perspective of information systems. His current preoccupations are with advancing an informing view of organization as a framework for research and teaching. In 2011, Bob is on sabbatical, travelling through Europe and North America, and enjoying research and teaching at different places in this wonderful world. :- 